\title{
VA and Medicare Utilization Among Dually Enrolled Veterans with Type 2 Diabetes: A Latent Class Analysis
}

\author{
Thomas R. Radomski, MD ${ }^{1,2}$, Xinhua Zhao, PhD'2, Carolyn T. Thorpe, PhD, MPH', , \\ Joshua M. Thorpe, PhD, MPH', , Chester B. Good, MD, MPH', 2,3,4, Maria K. Mor, PhD ${ }^{2,5}$, \\ Michael J. Fine, MD, MSc ${ }^{1,2}$, and Walid F. Gellad, MD, MPH ${ }^{1,2}$
}

'Division of General Internal Medicine, Department of Medicine, University of Pittsburgh School of Medicine, Pittsburgh, PA, USA; ${ }^{2}$ Center for Health Equity Research and Promotion, VA Pittsburgh Healthcare System, Pittsburgh, PA, USA; ${ }^{3}$ Department of Pharmacy and Therapeutics, University of Pittsburgh School of Pharmacy, Pittsburgh, PA, USA; ${ }^{4}$ Pharmacy Benefits Management Services, U.S. Department of Veterans Affairs, Hines, IL, USA; ${ }^{5}$ Department of Biostatistics, University of Pittsburgh, Pittsburgh, PA, USA.

BACKGROUND: Many Veterans treated within the VA Healthcare System (VA) are also enrolled in fee-for-service (FFS) Medicare and receive treatment outside the VA. Prior research has not accounted for the multiple ways that Veterans receive services across healthcare systems.

OBJECTIVE: We aimed to establish a typology of VA and Medicare utilization among dually enrolled Veterans with type 2 diabetes.

DESIGN: This was a retrospective cohort.

PARTICIPANTS: 316,775 community-dwelling Veterans age $\geq 65$ years with type 2 diabetes who were dually enrolled in the VA and FFS Medicare in 2008-2009.

METHODS: Using latent class analysis, we identified classes of Veterans based upon their probability of using VA and Medicare diabetes care services, including patient visits, laboratory tests, glucose test strips, and medications. We compared the amount of healthcare use between classes and identified factors associated with class membership using multinomial regression.

KEY RESULTS: We identified four distinct latent classes: class 1 (53.9\%) had high probabilities of VA use and low probabilities of Medicare use; classes 2 (17.2\%), 3 (21.8 $\%)$, and 4 (7.0\%) had high probabilities of VA and Medicare use, but differed in their Medicare services used. For example, Veterans in class 3 received test strips exclusively through Medicare, while Veterans in class 4 were reliant on Medicare for medications. Living $\geq 40$ miles from a VA predicted membership in classes 3 (OR 1.1, CI 1.06-1.15) and 4 (OR 1.11, CI 1.04-1.18), while Medicaid eligibility predicted membership in class 4 (OR 4.30, CI 4.10-4.51). CONCLUSIONS: Veterans with diabetes can be grouped into four distinct classes of dual health system use, representing a novel way to characterize how patients use multiple services across healthcare systems. This classification has applications for identifying patients facing differential risk from care fragmentation.

Prior Presentations This paper has been presented at the VA Health Services Research and Development Conference in Philadelphia, PA on 10 July 2015.

Electronic supplementary material The online version of this article (doi:10.1007/s11606-016-3631-4) contains supplementary material, which is available to authorized users.

Received August 6, 2015

Revised December 4, 2015

Accepted February 5, 2016

Published online February 22, 2016
KEY WORDS: utilization; diabetes; Veterans; Medicare; health services research.

J Gen Intern Med 31(5):524-31

DOI: $10.1007 / \mathrm{s} 11606-016-3631-4$

(c) Society of General Internal Medicine 2016

\section{BACKGROUND}

Many Veterans treated within the VA Healthcare System (VA) are also enrolled in non-VA health insurance and receive treatment outside the VA (i.e., dual use). As of 2010, $77 \%$ of Veterans enrolled in the VA had additional health benefits, with $51 \%$ enrolled in Medicare. ${ }^{1-3}$ Dual use is anticipated to increase as the Affordable Care Act and Veterans Choice Act enhance Veterans' access to outside care, ${ }^{4-7}$ and as more Veterans turn 65 and qualify for Medicare. ${ }^{3,8}$ Although dual use of VA and non-VA services may be essential to ensure that Veterans have access to timely and necessary care, it may also lead to fragmented medical care, ${ }^{9,10}$ increased healthcare utilization, and worse health outcomes. ${ }^{10-18}$

Most of the studies examining the impact of dual health system use focus on a specific type of medical service (e.g., outpatient visits), ${ }^{8,11,16-21}$ or classify dual use more generally as the receipt of any type of service in two health systems. ${ }^{8,10-}$ ${ }^{15,17-25}$ Yet, Veterans may use different services and to varying degrees within and outside the VA, making it inadequate to characterize dual users as a single group. This is particularly relevant for the one-quarter of all enrolled Veterans with type 2 diabetes. ${ }^{26}$ Given the multiple healthcare services inherent to diabetes care (e.g., outpatient visits, laboratory tests, glucose testing supplies, and medications) and prior studies that have linked broadly defined dual use of diabetes care with poor glycemic control and increased costs, ${ }^{25,27,28}$ diabetes is an ideal starting point to characterize dual use by considering multiple facets of care.

To fully understand the growing phenomenon of dual health system use among Veterans, it is first critical to understand the specific patterns in which dual users receive care within and outside the VA. Little is known about these patterns and their relationship to the quality and quantity of care received. In 
establishing a typology of VA and Medicare utilization among dually enrolled Veterans 65 years and older with type 2 diabetes, our aims were: (1) to use latent class analysis to categorize Veterans based upon their utilization of diabetesspecific services within the VA and Medicare; (2) to identify the factors that are associated with latent class membership; and (3) to compare the amount of utilization of diabetes health care services between latent classes.

\section{METHODS}

\section{Data Sources}

We performed a retrospective cohort study using linked national patient-level data from the VA and the Centers for Medicare and Medicaid Services (CMS) from fiscal years (FYs) 2008 and 2009 (1 October 2007 to 30 September 2009). This study was approved by the Institutional Review Board of the VA Pittsburgh Healthcare System.

VA data consisted of medical SAS (Statistical Analysis System) data sets for patient demographic data and diagnosis codes for all outpatient, inpatient, and emergency department visits; Decision Support Service data for laboratory tests; VA Pharmacy Benefits Management data for dispensed outpatient prescriptions and glucose test strips; and zip code data for distance to the nearest VA facility.

CMS data consisted of denominator files for Medicare and Medicaid enrollment and demographic variables; outpatient, inpatient, and carrier files for all outpatient, inpatient, emergency department, and laboratory claims; Part D event files for dispensed outpatient prescriptions; and durable medical equipment files for dispensed glucose test strips.

\section{Study Sample}

We previously identified a cohort of all 1,158,809 Veterans with type 2 diabetes and at least one outpatient visit within the VA in FY $2009 .{ }^{27-30}$ For this study, we restricted our analysis to Veterans from this cohort age 65 years and older with a documented diagnosis of type 2 diabetes in FY08, to ensure that each Veteran required diabetes care throughout all of FY09 $(\mathrm{n}=565,715)$. We excluded Veterans who were not enrolled in Medicare Parts A, B, or D ( $=5,030 ; 0.9 \%)$, and those enrolled in a Medicare HMO plan $(n=131,132 ; 23.2 \%)$, for whom we were unable to measure specific service use. We also excluded Veterans with a hospital or nursing home stay $>30$ days in FY09 ( $\mathrm{n}=29,849 ; 5.3 \%)$, as such stays were likely to disrupt the receipt of outpatient diabetes care. To focus on Veterans requiring medication treatment for diabetes, we also excluded 85,511 (15.1\%) who did not receive a diabetes medication from either the VA or Medicare in FY09.

\section{Diabetes Health Care Utilization}

We generated dichotomous indicators to represent any utilization of the following 6 diabetes-specific healthcare services within the VA and Medicare separately: outpatient visits, laboratory tests, glucose test strips, medications, inpatient admissions, and emergency department (ED) visits. Data for these indicators was fully available in both VA and Medicare data sets. We defined an outpatient visit as any face-to-face visit $^{31,32}$ associated with a primary ICD-9 diagnosis code for type 2 diabetes (online appendix Table 1), or any visit with a primary care physician or endocrinologist with a diagnosis code for type 2 diabetes in any coding position. ${ }^{28}$ We defined diabetes-specific laboratory tests as serum or point-of-care hemoglobin $\mathrm{A} 1 \mathrm{C}$ and urine microalbumin. We quantified the number of glucose test strips dispensed. We defined a diabetes medication as any oral or injectable hypoglycemic agent and quantified them using 30-day equivalents based on days' supply. We considered any inpatient admission and emergency department visit $^{33}$ that was associated with a primary diagnosis code for a diabetes-related diagnosis as previously defined. ${ }^{34}$ This array of 12 dichotomous indicators of diabetesspecific healthcare use in the VA and/or Medicare then served as the basis for the latent class analysis.

\section{Patient Characteristics}

We identified patient characteristics associated with membership in each latent class. ${ }^{27-29}$ Using VA data, we generated variables for age, sex, race and ethnicity. We classified race/ ethnicity as non-Hispanic white, black, Hispanic, or other using VA data supplemented by CMS enrollment data when needed. As proxies of socioeconomic and co-pay status, we determined each Veteran's Medicaid eligibility status and VA priority group (online appendix Tables $2 \mathrm{a}-\mathrm{b}$ ) ${ }^{35}$ We determined straight-line distance to the closest VA outpatient clinic from the central point of each Veteran's residential zip code, given the known association between distance and dual use. ${ }^{24} \mathrm{We}$ used ICD-9 codes recorded in both VA and CMS data to calculate the Charlson Comorbidity Index (excluding diabetes), ${ }^{36,37}$ number of diabetes complications (e.g., diabetic retinopathy, neuropathy, nephropathy, and peripheral vascular disease), and the presence of serious mental illness (online appendix Table 3).

\section{Statistical Analysis}

Latent Class Analysis (LCA). We applied LCA to the array of 12 dichotomous indicators of diabetes-specific healthcare services received in the VA and/or Medicare. LCA assumes that an array of observed categorical variables reflects a smaller number of latent variables that may be used to group subjects. ${ }^{38}$ In contrast to standard cluster analysis that uses more arbitrary clustering criteria, LCA may be applied to categorical variables and allows for rigorous statistical testing of model fit. Clustering Veterans in this manner also enables policies and interventions to be tailored to the specific needs of different subgroups. ${ }^{39}$ The goal of LCA in this study was to identify the smallest number of classes necessary to 
account for patterns of diabetes care utilization received by Veterans in the VA and/or Medicare.

The number of latent classes was determined iteratively, beginning with a one-class model and proceeding to test models with increasing numbers of classes. There is no gold standard for determining the optimal number of classes. Therefore, a combination of criteria was used, including: interpretability, clinical relevance, and the following statistical tests of model fit: log-likelihood, Bayesian Information Criterion (BIC), entropy, and boot-strapped likelihood ratio tests (LRT). ${ }^{38-40}$ In our final model, we assigned Veterans to the class that most closely matched their pattern of diabetes healthcare utilization (i.e., assigned to the class with the highest posterior class membership probability).

Patient Characteristics and Class Membership. After assigning Veterans to latent classes, we calculated the median and interquartile range for age, and the frequency and percent for all baseline categorical variables. To identify factors associated with latent class membership, we used multivariable multinomial logistic regression including all patient characteristics described above, using latent class 1 as the reference category.

Prevalence of Dual Use and Amount of Care Utilization. We calculated the percentage of dual users overall and for each diabetes healthcare service to explicitly show the prevalence of Veterans within each class who were dual users of VA and Medicare services. We also examined the amount of utilization for each diabetes care service overall, within the VA, and within Medicare, and compared differences across classes using the KruskalWallis Test.

The LCA was performed using MPlus version 6.11. All statistical comparisons among classes were performed using SAS version 9.3.

\section{RESULTS}

\section{Study Sample}

The final cohort contained 316,775 community-dwelling Veterans with type 2 diabetes who were age 65 years or older, dually enrolled in the VA and Medicare fee-for-service, used a diabetes medication, and had at least one VA outpatient visit for any reason in FY09. The median age was 74 years (IQR 69-80), $98.7 \%$ were male, and $83.0 \%$ were non-Hispanic white. Overall, $71.8 \%$ had a categorized Charleson Index $\geq 1$ and $47.6 \%$ had at least one diabetes complication (Table 1 ). Across all measured diabetes care services, $50.1 \%$ of Veterans used both VA and Medicare benefits for at least one diabetesspecific healthcare service (i.e., had any dual use for diabetes care).

\section{Latent Class Analysis}

After considering latent class models with two to eight classes, we determined that a four-class model had the best overall fit. The four-class model had a lower BIC and higher loglikelihood value than models with three or fewer classes, a statistically significant boot- strapped LRT $(p<0.001)$ over the three-class model, and the highest entropy statistic (0.86) for all models considered (online appendix Table 4). Given that inpatient hospitalizations and emergency department visits happened infrequently and did not significantly contribute to latent class membership, we removed these variables from the models.

Veterans in class $1(\mathrm{n}=170,750 ; 53.9 \%)$ were defined by their high probability of VA use and low probability of Medicare use across all facets of diabetes services (termed "VA predominant users") (Table 2). Veterans in class $2(n=54,606$; $17.2 \%$ ) had a high probability of VA use across all facets of care and a high probability of Medicare use for outpatient visits $(87.6 \%)$ and laboratory tests (47.6\%) (termed "VA+ Medicare outpatient service users"). Veterans in class 3 ( $\mathrm{n}=$ 69,$158 ; 21.8 \%$ ) had a nearly $0.0 \%$ probability of receiving glucose test strips from the VA, but $70.0 \%$ probability of receiving glucose test strips through Medicare (termed "VA+ Medicare test strip users"). Veterans in class $4(22,261 ; 7.0 \%)$ had a $49.7 \%$ probability of receiving a diabetes medication through the VA, but nearly a $100 \%$ probability of receiving a diabetes medication through Medicare (termed "VA+ Medicare prescription users").

Consistent with the LCA classes, only $7.8 \%$ of VA predominant users (class 1) were dual users of any diabetesspecific health service, whereas almost all VA+Medicare outpatient service users (class 2, $100 \%$ ), VA+ Medicare test strip users (class 3, $100 \%$ ), and VA + Medicare prescription users (class 4, $96.4 \%$ ) were dual users (Table 3). Over half of all VA+Medicare prescription users (class 4, $53.8 \%$ ) were dual users of diabetes medications.

\section{Characteristics of Latent Class Membership}

VA predominant users (class 1) were the youngest (median age 72 years, IQR 68-78) and had the largest proportions of black (13.5\%) or Hispanic $(6.7 \%)$ Veterans (Table 1). VA+ Medicare outpatient service users (class 2) had the highest percentage with a categorized Charleson Score of $\geq 1$ (78.1 $\%$ ), and $\geq 1$ diabetes complications (57.2\%). VA + Medicare test strip users (class 3) had the highest frequency of nonHispanic white $(91.0 \%)$ Veterans, and the highest percentage of Veterans in priority groups $7(3.2 \%)$ and $8(49 \%)$, requiring co-pays for healthcare services. VA + Medicare prescription users (class 4) had the highest frequency of Veterans who were Medicaid eligible (14.7\%), and lived greater than 40 miles from the nearest VA (6.0\%).

Our multivariable analyses demonstrated that Veterans who were older, male, had a Charleson Score of $\geq 1$, or $\geq 1$ diabetes complication, all had significantly higher odds of being in 
Table 1. Baseline Characteristics of Veterans with Diabetes by Latent Class of VA and Medicare Dual Use

\begin{tabular}{|c|c|c|c|c|c|}
\hline \multirow[t]{2}{*}{ Characteristic } & \multirow[t]{2}{*}{ Overall } & \multicolumn{4}{|c|}{ Latent Classes of Dual Use } \\
\hline & & $\begin{array}{l}\text { Class } 1 \text { (VA } \\
\text { Predominant) }\end{array}$ & $\begin{array}{l}\text { Class } 2 \text { (VA + } \\
\text { Medicare } \\
\text { Outpatient Services) }\end{array}$ & $\begin{array}{l}\text { Class } 3 \text { (VA + } \\
\text { Medicare Test } \\
\text { Strips) }\end{array}$ & $\begin{array}{l}\text { Class } 4 \text { (VA + } \\
\text { Medicare } \\
\text { Prescriptions) }\end{array}$ \\
\hline $\mathrm{N}(\%)$ & $\begin{array}{l}316,775 \\
(100)\end{array}$ & $170,750(53.9)$ & $54,606(17.2)$ & $69,158(21.8)$ & $22,261(7.0)$ \\
\hline Age in years, median (IQR) & $74(69-80)$ & $72(68-78)$ & $75(70-80)$ & $77(72-82)$ & $76(71-81)$ \\
\hline Male sex $(\%)$ & 98.7 & 98.5 & 98.9 & 98.9 & 98.9 \\
\hline \multicolumn{6}{|l|}{ Race/ethnicity (\%) } \\
\hline Non-Hispanic White & 83.0 & 77.6 & 86.8 & 91.0 & 90.7 \\
\hline Black & 10.0 & 13.5 & 7.5 & 4.9 & 4.6 \\
\hline Hispanic & 5.0 & 6.7 & 3.8 & 2.6 & 2.8 \\
\hline Other/missing & 2.0 & 2.3 & 1.9 & 1.5 & 2.0 \\
\hline Medicaid eligible (\%) & 5.3 & 6.0 & 3.5 & 2.1 & 14.7 \\
\hline \multirow{2}{*}{\multicolumn{6}{|c|}{ VA priority group $(\%)^{\dagger}$}} \\
\hline & & & & & \\
\hline 1 & 16.4 & 18.7 & 19.9 & 11.7 & 4.6 \\
\hline 2 & 4.6 & 5.2 & 4.7 & 3.6 & 3.1 \\
\hline 3 & 7.9 & 8.2 & 7.7 & 7.2 & 7.8 \\
\hline 4 & 4.6 & 5.4 & 4.0 & 3.3 & 4.7 \\
\hline 5 & 30.1 & 36.6 & 21.6 & 21.4 & 27.6 \\
\hline 6 & 0.6 & 0.6 & 0.5 & 0.5 & 0.6 \\
\hline 7 & 2.6 & 2.3 & 2.8 & 3.2 & 3.0 \\
\hline 8 & 33.3 & 23.1 & 38.8 & 49.0 & 48.6 \\
\hline \multicolumn{6}{|c|}{ Categorized Charleson Comorbidity Index (excluding DM) } \\
\hline 0 & 28.3 & 33.5 & 21.9 & 23.0 & 19.7 \\
\hline $1-2$ & 39.0 & 39.5 & 38.0 & 39.0 & 37.1 \\
\hline$\geq 3$ & 32.8 & 27.0 & 40.1 & 38.0 & 43.1 \\
\hline \multicolumn{6}{|l|}{ Diabetes complications $(\%)^{*}$} \\
\hline 0 & 52.5 & 57.8 & 42.9 & 49.3 & 45.4 \\
\hline $1-2$ & 31.4 & 29.9 & 33.8 & 32.6 & 33.2 \\
\hline$\geq 3$ & 16.2 & 12.4 & 23.4 & 18.1 & 21.5 \\
\hline Serious mental illness $(\%)^{\S}$ & 2.6 & 2.6 & 2.6 & 2.4 & 3.1 \\
\hline
\end{tabular}

* Distance to the nearest VA defined as the distance from the centroid of each Veteran's residential zip code to the nearest VA outpatient facility

${ }^{\dagger}$ Each Veteran is assigned to one of eight priority groups $(P G)$ upon VA enrollment, based upon such factors as service connection, era of service, and socioeconomic status determined by means testing. A Veteran's priority group determines the level of copays; For example, Veterans in PG1 have no copays, while those in PG7 and PG8 have co-pays for prescription drugs, inpatient, and outpatient care

${ }^{\ddagger}$ Including diabetic nephropathy, neuropathy, retinopathy, and diabetes-related peripheral vascular disease

${ }^{\S}$ Defined as a diagnosis of schizophrenia, schizoaffective disorder, bipolar disorder, delusion and paranoid disorders, and other non-organic psychoses as detected using ICD-9 codes

classes 2-4 versus class 1 (VA predominant users) (Table 4). Medicaid eligible Veterans had significantly higher odds of being VA+ Medicare prescription users (Class 4) (OR 4.30, CI 4.10-4.51). Veterans who lived 40 or more miles from a VA facility had significantly higher odds of being VA + Medicare test strip users (Class 3) (OR 1.1, CI 1.06-1.15) or VA+ Medicare prescription users (Class 4) (OR 1.11, CI 1.041.18). Compared to priority group 1 , Veterans in priority

Table 2. Predicted Probabilities of VA and Medicare Diabetes Health Services Use, by Latent Classes of Dual Use*

\begin{tabular}{|c|c|c|c|c|}
\hline \multirow[t]{2}{*}{ Diabetes-Specific Health Services } & \multicolumn{4}{|c|}{ Latent Classes of Dual Use } \\
\hline & $\begin{array}{l}\text { Class } 1 \text { (VA } \\
\text { Predominant) }\end{array}$ & $\begin{array}{l}\text { Class } 2 \text { (VA + Medicare } \\
\text { Outpatient Services) }\end{array}$ & $\begin{array}{l}\text { Class } 3 \text { (VA + Medicare } \\
\text { Test Strips) }\end{array}$ & $\begin{array}{l}\text { Class } 4 \text { (VA + Medicare } \\
\text { Prescriptions) }\end{array}$ \\
\hline $\mathrm{N}(\%):$ & $170,750(53.9)$ & $54,606(17.2)$ & $69,158(21.8)$ & $22,261(7.0)$ \\
\hline \multicolumn{5}{|l|}{ Within VA (\%): } \\
\hline Outpatient visits & 96.8 & 96.7 & 93.4 & 90.7 \\
\hline Laboratory tests & 95.2 & 86.0 & 78.3 & 68.2 \\
\hline Test strips & 72.6 & 100.0 & 0.0 & 18.5 \\
\hline Medications & 100.0 & 100.0 & 100.0 & 49.7 \\
\hline \multicolumn{5}{|l|}{ Within Medicare (\%): } \\
\hline Outpatient visits ${ }^{\dagger}$ & 7.4 & 87.6 & 78.9 & 83.7 \\
\hline Laboratory tests ${ }^{\star}$ & 0.0 & 47.6 & 43.0 & 49.6 \\
\hline Test strips ${ }^{8}$ & 4.3 & 20.4 & 70.0 & 70.4 \\
\hline Medications $\|$ & 0.8 & 7.5 & 2.1 & 100.0 \\
\hline
\end{tabular}

*Bolded probabilities represent those services that distinguish each latent class

${ }^{\dagger}$ Outpatient visits are defined as any face-to-face visit associated with a primary ICD-9 diagnosis code for type 2 diabetes (online appendix Table 1) or any visit with a primary care physician or endocrinologist with a diagnosis code for type 2 diabetes in any coding position

${ }^{7}$ Laboratory tests are defined as serum or point-of-care hemoglobin A1C and urine microalbumin

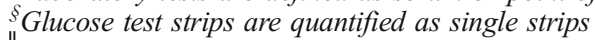

"Diabetes medications are defined as any oral or injectable anti-hyperglycemic agent and quantified using 30-days equivalents based on days' supply 
Table 3. Frequency of Dual Use (VA and Medicare) of Diabetes Health Services by Latent Classes of Dual Use*

\begin{tabular}{|c|c|c|c|c|c|}
\hline \multirow{2}{*}{$\begin{array}{l}\text { Diabetes-Specific of Health } \\
\text { Services }(\%)\end{array}$} & \multirow[t]{2}{*}{ Overall } & \multicolumn{4}{|c|}{ Latent Classes of Dual Use } \\
\hline & & $\begin{array}{l}\text { Class } 1 \text { (VA } \\
\text { Predominant) }\end{array}$ & $\begin{array}{l}\text { Class } 2 \text { (VA + } \\
\text { Medicare } \\
\text { Outpatient Services) }\end{array}$ & $\begin{array}{l}\text { Class } 3 \text { (VA+ } \\
\text { Medicare Test } \\
\text { Strips) }\end{array}$ & $\begin{array}{l}\text { Class } 4 \text { (VA + } \\
\text { Medicare } \\
\text { Prescriptions) }\end{array}$ \\
\hline N (\%) & $316,775(100)$ & $170,750(53.9)$ & $54,606(17.2)$ & $69,158(21.8)$ & $22,261(7.0)$ \\
\hline Any services & 50.1 & 7.8 & 100 & 100 & 96.4 \\
\hline Outpatient visits & 37.5 & 0.0 & 91.8 & 74.6 & 76.6 \\
\hline Laboratory tests ${ }^{\dagger}$ & 14.9 & 0.0 & 34.8 & 30.3 & 33.2 \\
\hline Glucose test strips & 5.1 & 2.6 & 16.4 & 0.0 & 13.0 \\
\hline Medications $\$$ & 5.2 & 0.9 & 5.5 & 0.0 & 53.8 \\
\hline
\end{tabular}

* Outpatient visits are defined as any face-to-face visit associated with a primary ICD-9 diagnosis code for type 2 diabetes (online appendix Table 1) or any visit with a primary care physician or endocrinologist with a diagnosis code for type 2 diabetes in any coding position

${ }^{\dagger}$ Laboratory tests are defined as serum or point-of-care hemoglobin AlC and urine microalbumin

${ }^{*}$ Glucose test strips are quantified as single strips

${ }^{\S}$ Diabetes medications are defined as any oral or injectable anti-hyperglycemic agent and quantified using 30-days equivalents based on days' supply

groups 7 and 8 had the highest odds of being VA+ Medicare prescription users (Class 4) (Table 4) (PG7 OR 5.23, CI 4.705.81; PG 8 OR 8.63 CI 8.07-9.23).

\section{Diabetes Care Utilization}

VA predominant users (Class 1) had significantly fewer total outpatient visits (median 3, IQR 2-5; $p<0.001$ ) than Veterans in all other classes, and used the fewest number of glucose test strips (100, IQR 0-300; $p<0.001)$ (Table 5). VA+Medicare test strip users (Class 3 ) received the fewest 30-day medication equivalents (12, IQR 9-20; $p<0.001)$, while VA+Medicare prescription users (Class 4 ) received the most (16.9 IQR 1225), the majority of which were filled through Medicare. Laboratory test utilization was similar across groups.

Table 4. Factors Associated with Dual Use Latent Class Membership Identified Using Multivariable Multinomial Logistic Regression

\begin{tabular}{|c|c|c|c|c|c|c|}
\hline & \multicolumn{2}{|c|}{ Class 2 vs. Class 1} & \multicolumn{2}{|c|}{ Class 3 vs. Class 1} & \multicolumn{2}{|c|}{ Class 4 vs. Class 1} \\
\hline & OR & $95 \% \mathrm{CI}$ & OR & $95 \% \mathrm{CI}$ & OR & $95 \%$ CI \\
\hline Age in years & 1.04 & $(1.04-1.05)$ & 1.08 & $(1.08-1.09)$ & 1.06 & $(1.06-1.07)$ \\
\hline Male Sex & 1.16 & $(1.06-1.27)$ & 1.24 & $(1.13-1.35)$ & 1.30 & $(1.14-1.49)$ \\
\hline \multicolumn{7}{|l|}{ Race/ethnicity } \\
\hline Non-Hispanic White & Ref & & Ref & & Ref & \\
\hline Black & 0.55 & $(0.53-0.57)$ & 0.42 & $(0.40-0.43)$ & 0.34 & $(0.32-0.37)$ \\
\hline Hispanic & 0.61 & $(0.58-0.64)$ & 0.45 & $(0.42-0.47)$ & 0.45 & $(0.42-0.49)$ \\
\hline Other & 0.80 & $(0.74-0.86)$ & 0.70 & $(0.65-0.76)$ & 0.94 & $(0.85-1.04)$ \\
\hline Medicaid eligibility & 0.88 & $(0.84-0.93)$ & 0.56 & $(0.52-0.59)$ & 4.30 & $(4.10-4.51)$ \\
\hline$>40$ miles to VA facility ${ }^{\dagger}$ & 0.95 & $(0.91-0.99)$ & 1.10 & $(1.06-1.15)$ & 1.11 & $(1.04-1.18)$ \\
\hline \multicolumn{7}{|l|}{ VA priority group } \\
\hline 1 & Ref & & ref & & Ref & \\
\hline 2 & 0.92 & $(0.88-0.97)$ & 1.15 & $(1.09-1.21)$ & 2.51 & $(2.27-2.77)$ \\
\hline 3 & 0.90 & $(0.86-0.94)$ & 1.31 & $(1.25-1.36)$ & 3.48 & $(3.21-3.77)$ \\
\hline 4 & 0.53 & $(0.51-0.56)$ & 0.74 & $(0.70-0.78)$ & 1.85 & $(1.69-2.03)$ \\
\hline 5 & 0.56 & $(0.54-0.58)$ & 0.92 & $(0.89-0.94)$ & 2.26 & $(2.11-2.42)$ \\
\hline 6 & 1.06 & $(0.93-1.21)$ & 1.67 & $(1.47-1.90)$ & 5.51 & $(4.54-6.68)$ \\
\hline 7 & 1.14 & $(1.07-1.21)$ & 2.04 & $(1.92-2.16)$ & 5.23 & $(4.70-5.81)$ \\
\hline 8 & 1.61 & $(1.56-1.65)$ & 3.14 & $(3.05-3.24)$ & 8.63 & $(8.07-9.23)$ \\
\hline \multicolumn{7}{|c|}{ Categorized Charleson Comorbidity Index (excluding DM) } \\
\hline 0 & ref & & Ref & & ref & \\
\hline $1-2$ & 1.37 & $(1.31-1.40)$ & 1.34 & $(1.30-1.37)$ & 1.49 & $(1.430-1.55)$ \\
\hline$\geq 3$ & 1.87 & $(1.82-1.92)$ & 1.71 & $(1.67-1.76)$ & 2.26 & $(2.167-2.35)$ \\
\hline \multicolumn{7}{|l|}{ Diabetes complications ${ }^{\S}$} \\
\hline 0 & ref & & Ref & & Ref & \\
\hline $1-2$ & 1.47 & $(1.44-1.51)$ & 1.27 & $(1.24-1.29)$ & 1.40 & $(1.353-1.45)$ \\
\hline$\geq 3$ & 2.35 & $(2.28-2.41)$ & 1.67 & $(1.62-1.72)$ & 2.09 & $(2.012-2.18)$ \\
\hline Serious mental illness & 1.00 & $(0.94-1.07)$ & 1.06 & $(1.00-1.13)$ & 1.25 & $(1.150-1.37)$ \\
\hline
\end{tabular}

*Abbreviations: CI - Confidence Interval, OR - Odds Ratio, VA - Veterans Affairs, DM - Diabetes Mellitus. Class 1: VA Predominant, Class 2: VA+ Medicare Outpatient Services, Class 3: VA + Medicare Test Strips, Class 4: VA + Medicare Prescriptions

${ }^{\prime}$ Distance to the nearest VA defined as the distance from the centroid of each Veteran's residential zip code to the nearest VA outpatient facility

${ }^{*}$ Each Veteran is assigned to one of eight priority group $(P G)$ upon VA enrollment based upon such factors as service connection, era of service, and socioeconomic status determined by means testing. A Veteran's priority group determines the level of copays; For example, Veterans in PG1 have no copays and those in PG7 and PG8 have co-pays for prescription drugs, inpatient, and outpatient care

${ }^{\xi}$ Including diabetic nephropathy, neuropathy, retinopathy, and diabetes-related peripheral vascular disease

Defined as a diagnosis of schizophrenia, schizoaffective disorder, bipolar disorder, delusion and paranoid disorders, and other non-organic psychoses as detected using ICD-9 codes 
Table 5. Magnitude of Diabetes Health Services used by Latent Classes of Dual Use*

\begin{tabular}{|c|c|c|c|c|}
\hline \multirow{2}{*}{$\begin{array}{l}\text { Diabetes-Specific Healthcare Service, } \\
\text { Median (IQR) }\end{array}$} & \multicolumn{4}{|l|}{ Latent Classes } \\
\hline & $\begin{array}{l}\text { Class } 1 \text { (VA } \\
\text { Predominant) }\end{array}$ & $\begin{array}{l}\text { Class } 2 \text { (VA + Medicare } \\
\text { Outpatient Services) }\end{array}$ & $\begin{array}{l}\text { Class } 3 \text { (VA + Medicare } \\
\text { Test Strips) }\end{array}$ & $\begin{array}{l}\text { Class } 4 \text { (VA + Medicare } \\
\text { Prescriptions) }\end{array}$ \\
\hline \multicolumn{5}{|l|}{ Outpatient visits $^{\dagger}$} \\
\hline Total & $3(2-5)$ & $5(4-8)$ & $4(3-6)$ & $5(3-7)$ \\
\hline VA & $3(2-5)$ & $2(1-4)$ & $2(1-3)$ & $1(1-2)$ \\
\hline Medicare & $0(0-0)$ & $3(1-4)$ & $2(1-4)$ & $3(1-5)$ \\
\hline \multicolumn{5}{|l|}{ Laboratory tests ${ }^{\ddagger}$} \\
\hline Total & $2(2-3)$ & $3(2-4)$ & $2(1-3)$ & $2(1-3)$ \\
\hline VA & $2(2-3)$ & $2(1-3)$ & $2(1-2)$ & $1(0-2)$ \\
\hline Medicare & $0(0-0)$ & $0(0-1)$ & $0(0-1)$ & $0(0-2)$ \\
\hline \multicolumn{5}{|l|}{ Test strips ${ }^{\S}$} \\
\hline Total & $100(0-300)$ & $250(100-600)$ & $300(0-600)$ & $300(100-700)$ \\
\hline VA & $100(0-300)$ & $200(100-550)$ & $0(0-0)$ & $0(0-0)$ \\
\hline Medicare & $0(0-0)$ & $0(0-0)$ & $300(300-600)$ & $300(300-600)$ \\
\hline \multicolumn{5}{|l|}{ Medications (30-day supplies) } \\
\hline Total & $14(10.2-22.6)$ & $15(11-23.2)$ & $12(9-20)$ & $16.9(12-25)$ \\
\hline VA & $14(10-22.3)$ & $14.6(10-22.1)$ & $12(9-20)$ & $3(0-12)$ \\
\hline Medicare & $0(0-0)$ & $0(0-0)$ & $0(0-0)$ & $11(5-15.4)$ \\
\hline
\end{tabular}

*All $p$ values were statistically significant at $p<0.001$ (Kruskal Wallis Test)

${ }^{\dagger}$ Outpatient visits are defined as any face-to-face visit associated with a primary ICD-9 diagnosis code for type 2 diabetes (online appendix Table 1) or any visit with a primary care physician or endocrinologist with a diagnosis code for type 2 diabetes in any coding position

Laboratory tests are defined as serum or point-of-care hemoglobin AlC and urine microalbumin

${ }^{\S}$ Glucose test strips are quantified as single strips

Diabetes medications are defined as any oral or injectable anti-hyperglycemic agent and quantified using 30-days equivalents based on days'supply

\section{DISCUSSION}

Using national data on all VA and Medicare dually enrolled Veterans receiving medical treatment for diabetes, we identified four distinct classes of dual enrollees, representing the most common patterns in which Veterans use diabetes health services. Across classes, we identified notable differences in demographics, Medicaid eligibility, VA co-pay requirements, distance to the nearest VA, and baseline health status. Each class also utilized different amounts of diabetes services overall, within the VA and within Medicare. These findings suggest that important differences in utilization patterns are missed when studies of dual use only examine individual types of service.

Our findings exemplify that there is no single type of "dual user." For example, VA + Medicare outpatient service users (class 2) and VA + Medicare test strip users (class 3) contained smaller percentages of Medicaid eligible Veterans than VA predominant users (class 1). This is consistent with prior studies that have associated dual use with higher income and educational attainment. ${ }^{14,15}$ In contrast, class 4 (VA+ Medicare prescription users) included more than double the percentage of Medicaid eligible Veterans than class 1 (VA Predominant Users), had the greatest amount of prescription dual users, and received a greater number of prescriptions from Medicare than all other classes. Medicaid enrollment, which enables Veterans to receive their prescriptions at low cost through Medicare Part D, is a significant enticement away from the VA for some Veterans. This finding is consistent with recent work demonstrating the impact of Medicaid expansion on decreasing VA utilization. ${ }^{41}$ Additionally, differences in copay requirements for Veterans in each priority group likely, in part, influenced in which system they received care. For example, a significant number of Veterans in priority groups 5 and 8 belonged to the "VA + Medicare Prescription user" class. Veterans in these classes had an \$8 copay for all VA prescription drugs and this cost may create an incentive to receive their prescriptions at lower cost through Medicare. ${ }^{42,43}$ These differences in Medicaid eligibility and priority group membership across classes highlight the heterogeneity among dual users.

We also discovered that distance to a VA is associated with membership in specific dual use classes. This finding is especially relevant given the recent passage of the Veterans Choice Act, in which enrolled Veterans who live greater than 40 miles from a VA facility may now utilize their VA benefits to receive care from non-VA providers. ${ }^{4}$ Veterans who lived 40 or more miles from VA facilities had greater odds of being VA+test strip users (class 3) or VA+Prescription Users (class 4) and received a greater number of test strips and medications through Medicare, respectively. Were these Veterans to now receive this care via the Choice Program instead of Medicare, the VA would likely encounter increased demand and costs for these services.

Our findings have important research, policy, and clinical implications. We have demonstrated that latent class analysis is a viable approach to precisely characterize the naturally occurring ways that Veterans' choose to receive care across healthcare systems, in contrast to prior studies that defined dual use in simpler terms. ${ }^{8,10-25}$ This characterization will enable researchers to more precisely control for and evaluate the impact of dual use on quality of care, paving the way for VA to target policies and interventions at Veterans in those groups at greatest risk of care fragmentation. Moreover, by recognizing the common characteristics associated with dual 
users in classes at greatest risk of care fragmentation, (e.g., dual medication users), the findings of this and other latent class analyses may be integrated into decision support tools to enable clinicians to more aggressively coordinate the care of certain Veterans and actively address their drivers of dual use.

This study has important limitations. First, these data only take into account the dual use of Veterans enrolled in the VA and fee-for-service Medicare. Veterans dually enrolled in Medicare Advantage or private insurance may exhibit different patterns of dual use. ${ }^{10}$ Second, prior studies have identified systemic under-coding of clinical conditions in the VA compared to Medicare claims data, and this could, in part, explain the increased number of diabetes complications and medical comorbidities attributed to dual users of Medicare services. $^{44-46}$ Third, our data is from fiscal years 2008 and 2009 , and may not reflect patterns of dual use that may have emerged with the implementation of more recent policies. Fourth, our cohort is composed of Veterans who are established VA patients. We therefore do not take into account those Veterans who are dually enrolled in the VA and Medicare but rely on Medicare services alone.

\section{CONCLUSIONS}

Using latent class analysis, we established a typology of four distinct classes representing the most common ways Medicare dually enrolled Veterans receive diabetes care. This represents a novel way to study the dually enrolled Veteran population and lays the foundation to more carefully characterize such Veterans on the basis of their dual healthcare utilization. This will enable VA to develop policies and interventions tailored to those dual enrollees most at risk of care fragmentation and mitigate the adverse outcomes of dual health system care.

Acknowledgements: This study was supported by a Career Development Award (CDA 09-207) from the U.S. Department of Veterans Affairs and a National Research Service Award from the Health Resources and Services Administration (T32HP22240). Support for VA/CMS data is provided by the Department of Veterans Affairs, Veterans Health Administration, Office of Research and Development, Health Services Research and Development, VA Information Resource Center (Project Numbers SDR 02-237 and 98-004).

Corresponding Author: Walid F. Gellad, MD, MPH; Center for Health Equity Research and PromotionVA Pittsburgh Healthcare System, University Drive, 151C, Pittsburgh, PA 15240, USA (e-mail: walid.gellad@va.gov).

\section{Compliance with ethical standards:}

Conflicts of Interest: The authors declare that they have no conflicts of interest.

\section{REFERENCES}

1. U.S. Department of Veterans Affairs. 2011 Survey of Veteran Enrollees' Health and Reliance Upon VA. Available at: http://www.va.gov/ healthpolicyplanning/soe2011/soe2011_report.pdf. Accessed: 5/24/2015.

2. Auerbach, ID, Weeks WB, Brantley I. "Healthcare Spending and Efficiency in the U.S. Department of Veterans Affairs." Rand Corporation, 2013.
3. Congressional Budget Office, Potential Costs of Veterans' Healthcare, Washington , D.C., 2010.

4. Veterans Access, Choice, and Accountability Act of 2014, Pub. L. no 113146, 128 Stat 1754 (2014). Print.

5. Veterans Choice Program Initial Report, compiled by the Veterans of Foreign Wars of the US. Available at http://www.vfw.org/uploadedFiles/VFW.org/ VFW_in_DC/VFWInitialReportonVeteransChoiceImplementation.pdf. Accessed May 14, 2015.

6. Patient Protection and Affordable Care Act, Pub. L no 111-148, 110 Stat 2033 (2010). Print.

7. Gellad WF. The Veterans Choice Act and dual heatlh system use. J Gen Intern Med. 2015. doi:10.1007/s11606-015-3492-2.

8. Hynes DM, Koelling $\mathbf{K}$, Stroupe $\mathbf{K}$, et al. Veterans' access to and use of Medicare and Veterans Affairs health care. Med Care. 2007;45(3):214-23.

9. Kizer KW. Veterans and the Affordable Care Act. JAMA. 2012;307(8):789-90.

10. Trivedi AN, Grebla RC, Jiang L, Yoon J, Mor V, Kizer KW. Duplicate federal payments for dual enrollees in Medicare Advantage plans and the Veterans Affairs health care system. JAMA. 2012;308(1):67-72.

11. Wright SM, Daley J, Fisher ES, Thibault GE. Where do elderly veterans obtain care for acute myocardial infarction: Department of Veterans Affairs or Medicare? Health Serv Res. 1997;31(6):739-54.

12. Wolinsky FD, An H, Liu L, Miller TR, Rosenthal GE. Exploring the association of dual use of the VHA and Medicare with mortality: separating the contributions of inpatient and outpatient services. BMC Health Serv Res. 2007;7(1):70.

13. Liu CF, Bolkan C, Chan D, Yano EM, Rubenstein LV, Chaney EF. Dual use of VA and non-VA services among primary care patients with depression. J Gen Intern Med. 2009;24(3):305-11.

14. Shen Y, Findley PA, Maney M, et al. Department of Veterans AffairsMedicare dual beneficiaries with stroke: where do they get care? J Rehabil Res Dev. 2008;45(1):43-51.

15. Zhu CW, Penrod JD, Ross JS, Dellenbaugh C, Sano M. Use of Medicare and Department of Veterans Affairs health care by veterans with dementia: a longitudinal analysis. J Am Geriatr Soc. 2009;57(10):1908-14.

16. Jia H, Zheng Y, Reker DM, et al. Multiple system utilization and mortality for veterans with stroke. Stroke. 2007;38(2):355-60.

17. Wolinsky FD, Miller TR, An H, Brezinski PR, Vaughn TE, Rosenthal GE. Dual use of Medicare and the Veterans Health Administration: are there adverse health outcomes? BMC Health Serv Res. 2006;6(1): 131.

18. Tarlov E, Lee TA, Weichle TW, et al. Reduced overall and event-free survival among colon cancer patients using dual system care. Cancer Epidemiol Biomarkers Prev. 2012;21(12):2231-41.

19. Humensky J, Carretta H, de Groot K, Brown MM, Tarlov E, Hynes DM. Service utilization of veterans dually eligible for VA and Medicare fee-forservice: 1999-2004. Medicare Medicaid Res Rev. 2012;2(3).

20. Wang V, Maciejewski ML, Patel UD, Stechuchak KM, Hynes DM, Weinberger M. Comparison of outcomes for veterans receiving dialysis care from VA and non-VA providers. BMC Health Serv Res. 2013;13(1):26.

21. Ajmera M, Wilkins TL, Sambamoorthi U. Dual Medicare and Veteran Health Administration use and ambulatory care sensitive hospitalizations. J Gen Intern Med. 2011;26(Suppl 2):669-75.

22. Grubaugh AL, Magruder KM, Zinzow HM, Frueh BC. Use of dual health care services among veterans seen in Veterans Affairs primary care clinics. Gen Hosp Psychiatry. 2009;31(6):589-91.

23. Ross JS, Keyhani S, Keenan PS, et al. Dual use of Veterans Affairs services and use of recommended ambulatory care. Med Care. 2008;46(3):309-16.

24. Carey K, Montez-Rath ME, Rosen AK, Christiansen CL, Loveland S, Ettner SL. Use of VA and Medicare services by dually eligible veterans with psychiatric problems. Health Serv Res. 2008;43(4):1164-83.

25. Helmer D, Sambamoorthi U, Shen Y, et al. Opting out of an integrated healthcare system: dual-system use is associated with poorer glycemic control in veterans with diabetes. Prim Care Diabetes. 2008;2(2):73-80.

26. Diabetes GUERI. Available at http://www.queri.research.va.gov/dm/. Last accessed July 16, 2015.

27. Gellad WF, Donohue JM, Zhao X, et al. Brand-name prescription drug use among Veterans Affairs and Medicare Part D patients with diabetes: a national cohort comparison. Ann Intern Med. 2013;159(2):105-14.

28. Gellad WF, Zhao X, Thorpe CT, Mor MK, Good CB, Fine MJ. Dual use of department of veterans affairs and medicare benefits and use of test strips in veterans with type 2 diabetes mellitus. JAMA Intern Med. 2015;175(1):26-34.

29. Gellad WF, Mor M, Zhao X, Donohue J, Good C. Variation in use of highcost diabetes mellitus medications in the VA healthcare system. Arch Intern Med. 2012;172(20):1608-11.

30. Thorpe CT, Gellad WF, Good CB, et al. Tight glycemic control and use of hypoglycemic medications in older veterans with type 2 diabetes and comorbid dementia. Diabetes Care. 2015;38(4):588-95. 
31. Pham HH, Schrag D, O'Malley AS, Wu B, Bach PB. Care patterns in Medicare and their implications for pay for performance. N Engl J Med. 2007;356(11):1130-9.

32. Thorpe CT, Flood GE, Kraft SA, Everett CM, Smith MA. Effect of patient selection method on provider group performance estimates. Med Care. 2011;49(8):780-5.

33. Merriman K, Caldwall D. "How to identify emergency room services in the Medicare claims data," Research Data Assistance Center, Center for Medicare and Medicaid Services, Technical Publication TN-003, July 2012. http://www.resdac.org/resconnect/articles/144. Last accessed 6/29/2015.

34. Menzin J, Korn JR, Cohen J, et al. Relationship between glycemic control and diabetes-related hospital cost in patients with type 1 or 2 diabetes mellitus. J Manag Care Pharm. 2010;16(4):264-75.

35. Health Benefit Copays. Available at http://www.va.gov/ HEALTHBENEFITS/cost/copays.asp. Last accessed June 29, 2015.

36. Charlson ME, Pompei P, Ales KL, MacKenzie CR. A new method of classifying prognostic comorbidity in longitudinal studies: development and validation. J Chronic Dis. 1987;40(5):373-83.

37. Charlson M, Szatrowski TP, Peterson J, Gold J. Validation of a combined comorbidity index. J Clin Epidemiol. 1994;47(11):1245-51.

38. Collins LM, Lanza ST. Latent class and latent transition analysis. Hoboken, New Jersey: Wiley; 2010.
39. Thorpe JM, Thorpe CT, Kennelty KA, Pandhi N. Patterns of perceived barriers to medical care in older adults: a latent class analysis. BMC Health Serv Res. 2011;11(1): 181.

40. Trivedi RB, Ayotte BJ, Thorpe CT, Edelman D, Bosworth HB. Is there a nonadherent subtype of hypertensive patient? A latent class analysis approach. Patient Prefer Adherence. 2010;4:255-62.

41. Frakt AB, Hanchate A, Pizer SD. The effect of Medicaid expansions on demand for care from the Veterans Health Administration. Healthcare.2015.http://www.sciencedirect.com/science/article/pii/ S2213076415000202. Last Accessed 7/17/2015.

42. Metformin - Prices. Available at http://www.goodrx.com/metformin. Last accessed November 5, 2015.

43. Glipizide - Prices. Available at http://www.goodrx.com/glipizide. Last accessed November 5, 2015.

44. Rosen AK, Gardner J, Montez M, Loveland S, Hendricks A. Dual-system use: are there implications for risk adjustment and quality assessment? Am J Med Qual. 2005;20(4):182-94.

45. Byrne MM, Kuebeler M, Pietz K, Petersen LA. Effect of using information from only one system for dually eligible health care users. Med Care. 2006;44(8):768-73.

46. Petersen LA, Byrne MM, Daw CN, Hasche J, Reis B, Pietz K. Relationship between clinical conditions and use of Veterans Affairs health care among Medicare-enrolled veterans. Health Serv Res. 2010;45(3):762-91. 